\title{
Graves Disease Associated with Myasthenia Gravis: A Pediatric Case Report
}

\author{
Orsolya Juhász*, Miklós Garami, Ágnes Herczegfalvi and Ágnes Sallai \\ Semmelweis University, 2nd Department of Pediatrics, Hungary
}

Submission: May 31, 2021; Published: June 11, 2021

*Corresponding author: Orsolya Juhász, Semmelweis University, 2nd Department of Pediatrics, Túzoltó street 7-9. Budapest, 1094 Hungary

Abstract

The presence of Graves Disease and hyperthyroidism may obscure the diagnosis of associated myasthenia gravis due to the symptom similarity. We presented a case of a 11-year-old girl with the sypmtoms of swallowing- and breathing difficulties, palpitation and fatigue. Firstly, we could prove the presence of Graves disease in the backround but the patient's symptoms worsened and became more severe. Finally, we diagnosed the coexistence of Graves disease and myasthenia gravis behind the confusing symptoms, which association counts very rare in childhood.

Keywords: hyperthyroidism, pseudobulbar paresis, thyreostatics, ß-blockers, autoimmune associations

Abbreviation: Ach:Acetylcholine; AchR: Acetylcholine Receptor; AI: Autoimmune; ATPO: Anti-Thyreoperoxidase Anibody; EMG: Eectromyography; fT4: Free Thyroxne; GD: Basedow-Graves Disease; HLA: Human Leukocyte Antigen; MG: Myasthenia Gravis ; RR: Blood Pressure; TPP: Thyrotoxic Periodic Hypokalaemic Paralysis; TRAK: Anti-TSHR Antibody; TSH: Thyroid-Stimulating Hormone; TSHR: Thyroid-Stimulating Hormone Receptors

\section{Introduction}

Basedow-Graves disease (GD) is an inflammatory thyroid disease with an autoimmune (AI) mechanism in which autoantibodies to thyroid-stimulating hormone (TSH) receptors (TSHR) appear in the circulation (along with other anti-thyroid autoantibodies), thereby pathologically stimulating thyroid function. As a result, on one hand, the level of free thyroid hormones increases, which can take on extreme levels as thyrotoxicosis, and on the other hand, causing the proliferation of thyroid stock can lead to the formation of diffuse goiter [1]. The prevalence of Basedow disease in Hungary, which accounts for more than $95 \%$ of non- congenital hyperthyroidism cases, is close to $0.1 \%$ among school-age children. The girl-to- boy ratio is 5: 1 , most commonly occurring in adolescence [2].

Thyrotoxic periodic hypokalaemic paralysis (TPP) may occur in thyrotoxicosis, especially in GD. Shub mostly occurs as acute, reversible weakness in proximal muscles with the involvement of the bulbar and eye muscles. Toxic paralysis is characterized by hypokalemia, which can be a serious, life-threatening complication not only due to respiratory failure because of respiratory muscle weakness, but also due to the risk of arrhythmia [3].
Myasthenia gravis (MG) is a disease associated with AImediated damage to the postsynaptic membrane of the neuromuscular junction and fatigue muscle weakness. In $85 \%$ of cases, autoantibodies against the acetylcholine receptor (AchR) are produced, preventing acetylcholine (Ach) binding, thus signaling from the nerve end to the striated muscle [4].

Myasthenia gravis can occur at any age and in any sex. According to a review, the incidence of MG in Europe is estimated at $30 / 100,000 /$ year [5].

The coexistence of the two diseases is known in the literature, however, only a few case studies on the pediatric aspect have been reported so far [6,7]. The incidence of autoimmune thyroid disease is relatively common in patients with MG (5-10\%), however, the association between GD and MG is only $0.14 \%$ [8]. The subjective symptoms described in GD, such as difficulty swallowing, shortness of breath, and thyrotoxic periodic hypokalaemic paralysis in thyrotoxicosis, may make more difficulties in diagnosis, the clinician should consider the possibility of this rare correlation $[9,10]$. 


\section{The Case and the Results}

An 11-year-old girl reported dull attention and weight loss to her pediatrician, who perceived an enlarged thyroid during the physical examination, and referred her to an endocrinologist and to the 2nd Department of Pediatrics, Semmelweis University.

At the time of the first endocrinological detection, there was no difference in the status besides the enlarged, more palpable thyroid gland after swallowing. Height $(152.5 \mathrm{~cm})$ was at the 75 -
90 percentile and body weight $(36.9 \mathrm{~kg})$ at the $25-50$ percentile. Her puberty, according to Tanner, was A2B1-2P2. On the thyroid ultrasound and Doppler ultrasound examination, enlarged lobes, inhomogeneous echo structure, markedly increased flow was described, which was consistent with the image of autoimmune thyroiditis (Figure 1). Blood sample was taken to measure thyroid function (TSH, fT4) and autoantibodies (ATPO, TRAK), then the currently asymptomatic child in good general condition was sent home.

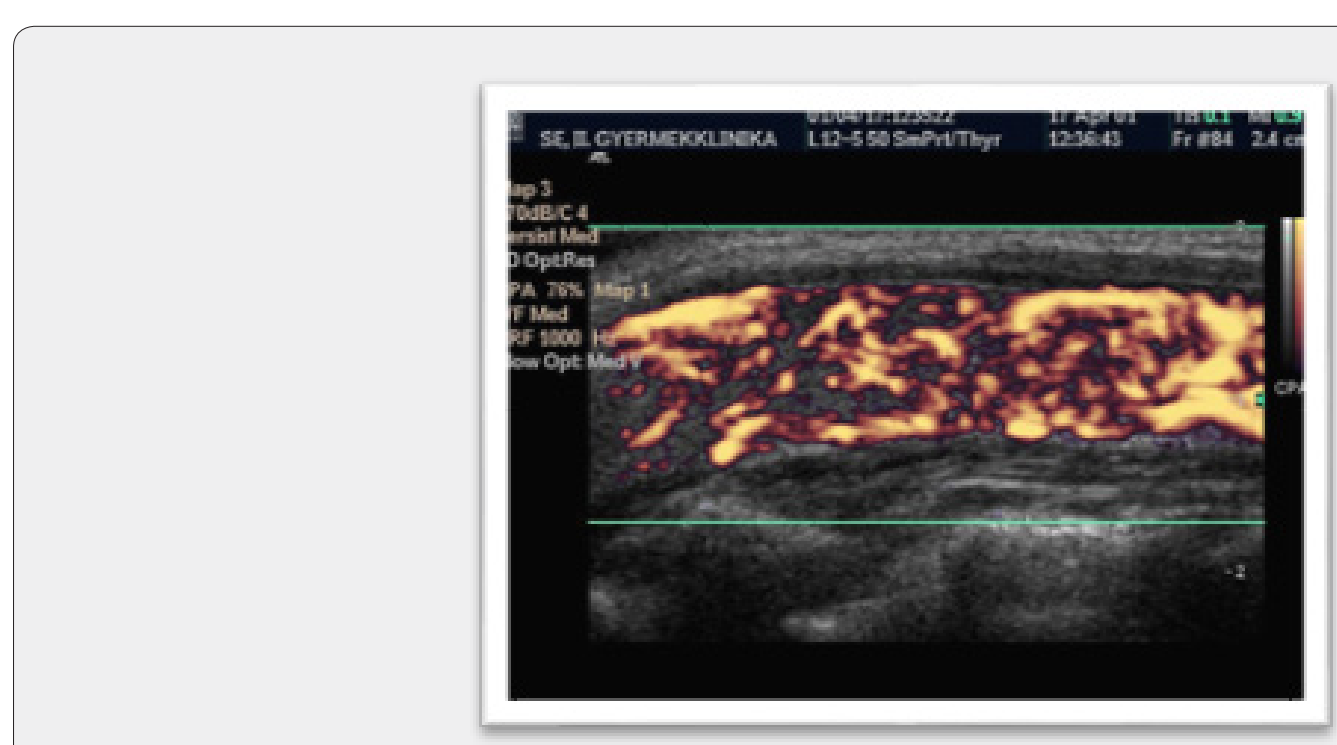

Figure 1: Thyroid ultrasound and Doppler ultrasound: enlarged lobes, inhomogeneous echo structure, markedly increased flow was described. This picture corresponds to autoimmune thyroiditis.

She showed up at our department that night again, due to difficulty of swallowing, vomiting, and fast heartbeat. In addition to the abnormality observed a few hours earlier in her status, her worsening general condition, tachycardia, elevated systolic blood pressure, coated tongue, dry skin, and ball-shaped tonsils should be highlighted. During 24-hour blood pressure monitoring, systolic blood pressure values greater than the 95th percentile relative to body height were detected (RR (mean): 129/74mmHg). Free thyroid hormone levels measured from a previously taken sample were elevated (fT4: 42.06pmol / l, fT3: $40.1 \mathrm{pmol} / \mathrm{l}$ ) with a markedly suppressed TSH value (TSH: $0.000 \mathrm{mE} / \mathrm{l}$ ). ATPO levels were found to be high (ATPO: 395.70U/ml), TRAK measurements were still ongoing. Despite the background of the clinical picture, thyrotoxicosis was suspected, and propranolol and thiamazole therapy were initiated accordingly. In addition to the treatment applied, her complaints were alleviated and her general condition showed a marked improvement, and after four days she was discharged.

10 days later, she was transported to our department by an ambulance helicopter due to difficulty breathing and shortness of breath. Since the previous hospitalization, vomiting has occurred once or twice every day. At the time of admission, tachycardia, elevated systolic blood pressure, coated tongue, dry skin, ball-shaped tonsils, an enlarged, compact, tactile thyroid gland were observed, and his lips were potted, his mucous membranes were faint, and his facial mucus was poor. At our Endocrinology Ward, vomiting did not recur, however, she was not able to cough up the secretions accumulating in the airways, despite repeated humidification and aspiration. Decrease in saturation and disturbance of consciousness occurred, so we placed her at our Intensive Care Unit. The clinical picture was dominated by an undulating inability to swallow, cough, and an intermittent oxygen demand. She could only empty her airway and pharyngeal secretions by aspiration. Neurological consultation raised the possibility of myasthenia syndrome (paraneoplastic or parainfunctional), and a positive Tensilon test was also mentioned. The neoplastic process has not been confirmed by laboratory tests or imaging. The clinical picture suggested pseudobulbar paresis. Chemical and sediment testing of the cerebrospinal fluid proved to be normal, and the possibility of autoimmune encephalitis was excluded by the negativity of the autoantibodies. EMG examination did not provide a definitive diagnosis. We started shock steroid therapy and plasmapheresis. We could extubate her after the first plasmapheresis treatment, but the clinic did not change significantly. We temporarily used non-invasive ventilation; however, we were forced to reintubate 
due to secretion retention and ineffective cough. With continued treatment (she received plasmapheresis treatment a total of five times), her muscle strength showed an improving tendency, so we extubated her without any problems. She temporarily required the administration of masked oxygen, but her swallowing and coughing, his general condition improved spectacularly, and her need for masked oxygen ceased. Meanwhile, serological testing confirmed fresh Mycoplasma infection. Trigger or direct neurotoxic effects of the pathogen were also reported; therefore, clarithromycin treatment was used.

During further care in the open ward, her general condition gradually improved. In addition to the thyrostatic treatment used, fT4 decreased to the normal range with still suppressed TSH, so treatment with thiamazole could be reduced to the maintenance dose. TRAK was also positive from the sample taken at the first visit, so we established the diagnosis of Basedow-Graves disease against the background of hyperthyroid autoimmune thyroiditis. As a result of the performed plasmapheresis, the upper cerebral nerve symptoms and respiratory distress observed in the intensive care unit were significantly reduced, however, peripheral muscle weakness occurred. Pyridostigmine therapy was started in addition her muscle strength gradually improved. Repeated EMG examination indicated a 30\% decrement in the upper limb, confirming the diagnosis of myasthenia syndrome. Furthermore, the anti-Ach receptor antibody test taken from a blood sample before the shock steroid treatment also showed an extremely high value. Based on these, the deterioration requiring intensive ward treatment was considered to be a myasthenic crisis. Longterm immunosuppressive therapy was initiated with azathioprine adjustment. After a total of twenty days after hospitalization, the patient was discharged from hospital.

In 2.5 months, we needed to hospitalize her due to difficulty swallowing, fading voice presentation symptoms, which presented another myasthenic crisis. She also experienced weight loss; her free thyroid hormone levels were elevated again, still with suppressed TSH despite the prescribed treatment.

Given that difficult-to-control comorbid autoimmune diseases were present, thymectomy and subtotal thyroidectomy were performed in one session based on endocrinological, neurological, surgical, multidisciplinary consultation.

Following thyroidectomy, sustained euthyroidism was achieved with thyroid hormone replacement.

After the removal of the thymus, its neurological symptoms persisted with undulating severity. In addition to pyridostigmine, she was treated with steroids, later rituximab, and azathioprine, which required hospitalization for neutropenic fever on several occasions. Immunosuppression was stopped 2.5 years after surgery. Pyridostigmine therapy could also be stopped nearly five years after thymectomy, so currently, MG does not cause any complaints to the patient with drug relief and she has no neurological symptoms.
In order to clarify the background of the association between the two diseases, we performed HLA typing according to the literature. The presence of HLA-DQ8, a split antigen of HLA-DQ3 serotype was confirmed.

\section{Discussion}

In the case described above, the progression of neurological symptoms in the presence of hyperthyroidism, then of unknown origin, followed by thyrotoxicosis led to respiratory failure. Symptoms of hyperthyroidism and possible thyrotoxic periodic hypokalaemic paralysis, as well as encephalitis, a rare complication of Hashimoto's thyroiditis, which could not be ruled out at the time, may have explained the deterioration. The possibility of autoimmune encephalitis was excluded because of the negativity of autoantibodies measured from the cerebrospinal fluid and based on the clinical picture. The neurological consultation suggested the possible causal role of MG, which was subsequently confirmed. In our case, antibodies against AchR were detected, which is less common compared to cases of MG not associating other autoimmune entities [8]. The literature also draws attention to the difficulty of differential diagnosis due to symptomatic similarity $[10,11]$.

In the presence of GD, high levels of free thyroid hormone impair neuromuscular signaling and therefore may worsen the symptoms and clinical course of MG, as we assume, in patients with therapy-resistant MG for the first time, progressing to respiratory failure. Also, one of the described side-effects of ß-blockers prescribed for tachycardia associated with thyrotoxicosis is an exacerbation of the symptoms and course of MG $[12,13]$.

In the case we described the course of the two autoimmune diseases was severe, and the therapeutic response in both entities was poor and inadequate. One study found that the coexistence of the two diseases did not affect therapeutic efficacy, with immunosuppression, which improved the clinical picture of both diseases. The authors found that thymectomy did not affect hyperthyroidism [14], however, there is also an example in the literature that the course of associated autoimmune diseases was also improved by thymus removal [15].

However, in the case in this study, MG was difficult to control even after thymectomy. The effect of the intervention on GD could not be studied because a thyroidectomy was also performed in one session, thus eliminating the body's production of the thyroid hormone. In the course of MG, the latter intervention did not change significantly either, despite the emergence of a euthyroid condition and the fact that a ß-blocker could be omitted.

There are no clear resolutions in the literature on the exact background, cause, and pathomechanism of the joint occurrence of the two entities. Can the manifestation of GD and MG in a patient be explained by Hickam's dictum or Occam's razor? According to the former principle, the two diseases appeared independently, side by side, and like other autoimmune disease associations, it is an 
overlap syndrome. One study investigated the structural homology of thyroglobulin and acetylcholinesterase and the resulting pathogenic and aggravating role of cross-reactive antibodies in the presence of autoantibodies characteristic of these two autoimmune diseases $[16,17]$. According to the latter philosophical principle, cleaving with Occam's razor in the spirit of simplification, it was assumed that the two diseases could be traced back to one causal factor, ultimately one entity. The literature mentions a description of autoimmune polyglandular disease syndrome (APS) type IIIc, which, among other autoimmune phenomena, corresponds to the disease association we have described, thus manifesting itself incompletely in our patient [6]. The formation of APS IIIc is explained by a DLA / DR mutation in HLA in the region that regulates antigen presentation to $\mathrm{T}$ cells [18]. Besides, a multicase study confirmed the presence of a common HLA type (HLADQ3) in patients with both confirmed GD and MG [19] which was also confirmed in the case of our patient. Given the low number of cases in the studies, none of the principles is conclusive, and the position on the exact pathomechanism of the association between GD and MG is not clear in the literature.

\section{Conclusion}

a) The presence of GD and hyperthyroidism may obscure the diagnosis of associated MG due to the symptom similarity, therefore it is a clinical task to think about the possible association of MG in case of progression and neurological symptoms.

b) Hyperthyroidism and administration of ß-blockers may worsen the symptoms of MG, so co-occurrence of the two diseases may result in poorer prognosis and therapeutic response.

\section{Conflict of Interest}

a) The authors have no conflicts of interest to declare.

b) The manuscript entitled "Graves disease associated with myasthenia gravis: a pediatric case report" represents valid work; neither this manuscript nor one with substantially similar content under our authorships has been published or is being considered for publication elsewhere; and copies of any closely related manuscripts are enclosed in the manuscript submission.

c) The authors agree to allow the corresponding author to serve as the primary correspondent with the editorial office and to review and sign off on the final proofs prior to publication.

d) Any change in authors and/or contributors after initial submission will be approved by all authors. This applies to additions, deletions, change in order of the authors, or contributions being attributed differently. Any alterations will be explained.

The authors confirm that this work is an accurate representation of the reported case.

\section{References}

1. Weetman AP (2000) Graves' disease. New England Journal of Medicine 343(17): 1236-1248.

2. (2009) Az Egészségügyi Minisztérium szakmai protokollja A pajzsmirigyműködés zavarairól; Csecsemő- és Gyermekgyógyászati Szakmai Kollégium.

3. McFadzean AJ, Yeung R (1967) Periodic paralysis complicating thyrotoxicosis in Chinese. British Medical Journal 1(5538): 451-455.

4. Aknin SB, Cuvelier MF, Eymard B (2014) Diagnostic and clinical classification of autoimmune myasthenia gravis. Journal of autoimmunity 48: 143-148.

5. McGrogan A, Sneddon S, De Vries CS (2010) The incidence of myasthenia gravis: a systematic literature review. Neuroepidemiology 34(3): 171-183.

6. Bossowski A, Jamiolkowska M, Furmaniak J, Smith BR (2016) 15-YearOld Girl with APS Type IIIc, with Post-Thymectomy RemissionCase Report. In 55th Annual ESPE. European Society for Paediatric Endocrinology Vol. 86.

7. Koves IH, Cameron FJ, Kornberg AJ (2009) Ocular myasthenia gravis and Graves disease in a 10-year-old child. Journal of Child Neurology 24(5): 615-617.

8. Chen YL, Yeh JH, Chiu HC (2013) Clinical features of myasthenia gravis patients with autoimmune thyroid disease in Taiwan. Acta Neurologica Scandinavica 127(3): 170-174.

9. Sehgal S, Rebello R, Wolmarans L, Elston M (2017) Hickam's dictum: Myasthenia Gravis presenting concurrently with Graves' disease. BMJ Case Reports 2017.

10.Aszalós Z (2007) Néhány endokrin betegség neurológiai és pszichiátriai vonatkozása: A pajzsmirigy= Some neurological and psychiatric complications in the disorders of the thyroid gland. Orvosi Hetilap 148(7): 303-310.

11. Tanwani LK, Lohano V, Ewart R, Broadstone VL, Mokshagundam SPL (2001) Myasthenia gravis in conjunction with graves'disease: a diagnostic challenge. Endocrine Practice 7(4): 275-278.

12. Rajasekaran D, Chandrasekar S, Rajendran M (2006) Drug related crisis in myasthenia gravis. JAPI 54: 802-821.

13. Lakhal K, Blel Y, Fysekidis M, Mohammedi K, Bouadma L (2008) Concurrent Graves disease thyrotoxicosis and myasthenia gravis: the treatment of the former may dangerously reveal the latter. Anaesthesia 63(8): 876-879.

14. Ratanakorn D, Vejjajiva A (2002) Long- term follow- up of myasthenia gravis patients with hyperthyroidism. Acta Neurologica Scandinavica 106(2): 93-98.

15. Zenteno JFT, Cardenas G, Estanol B, Ramos GG, Cisneros NW (2004) Associated conditions in myasthenia gravis: response to thymectomy. European Journal of Neurology 11(11): 767-773.

16. Mappouras DG, Philippou G, Haralambous S, Tzartos SJ, Balafas A, et al. (1995) Antibodies to acetylcholinesterase cross- reacting with thyroglobulin in myasthenia gravis and Graves' disease. Clinical \& Experimental Immunology 100(2): 336-343.

17. Sekiguchi Y, Hara Y, Takahashi M, Hirata Y (2005) Reverse 'seesaw'relationship between Graves' disease and myasthenia gravis; clinical and immunological studies. Journal of Medical and Dental Sciences 52(1): 43-50. 
18. Swillens S, Ludgate M, Marcken L, Dumont JE, Vassart G (1986) Analysis of sequence and structure homologies between thyroglobulin and acetylcholinesterase: possible functional and clinical significance. Biochemical and Biophysical Research Communications 137(1): 142 148.
19. Sperling M, Yau M (2017) Autoimmune polyglandular syndromes. In Endotext [Internet].
This work is licensed under Creative

Commons Attribution 4.0 License

DOI: 10.19080/JOJCS.2021.12.555838

\section{Your next submission with Juniper Publishers} will reach you the below assets

- Quality Editorial service

- Swift Peer Review

- Reprints availability

- E-prints Service

- Manuscript Podcast for convenient understanding

- Global attainment for your research

- Manuscript accessibility in different formats

( Pdf, E-pub, Full Text, Audio)

- Unceasing customer service

Track the below URL for one-step submission https://juniperpublishers.com/online-submission.php 